\title{
A common origin for immunity and digestion
}

\author{
Nichole A. Broderick* \\ Department of Molecular, Cellular, and Developmental Biology, Yale University, New Haven, CT, USA
}

\author{
Edited by: \\ Abhay Satoskar, The Ohio State \\ University, USA
}

Reviewed by:

Laurel L. Lenz, University of Colorado

School of Medicine, USA

Dina Weilhammer, Lawrence

Livermore National Laboratory, USA

*Correspondence:

Nichole A. Broderick, Department of

Molecular, Cellular, and

Developmental Biology, Yale

University, PO Box 208103, MCDB

KBT 908, New Haven, CT 06520, USA

e-mail: nabroderick@gmail.com
Historically, the digestive and immune systems were viewed and studied as separate entities. However, there are remarkable similarities and shared functions in both nutrient acquisition and host defense. Here, I propose a common origin for both systems. This association provides a new prism for viewing the emergence and evolution of host defense mechanisms.

Keywords: innate immunity, host-microbe interactions, gut microbiome, evolution, metabolism, digestion physiology
The immune system appeared early in the evolution of metazoa and is thought to have originated to protect the greater investment of multi-cellularity $(1,2)$. Currently, two views have been suggested for the origin of the immune system. One view is that the immune system emerged to protect against invasive microbes (3, 4). Recently, an alternative hypothesis proposed that the immune system emerged to manage the microbiota (5-7). In this essay, I suggest a third selection pressure, not exclusionary of the other views that focus on function. I propose a common origin for the digestive and immune systems that traces their ancestry to the quest for more efficient energy acquisition.

\section{IN THE BEGINNING, DIGESTION AND IMMUNITY WERE ONE...}

Over a century ago, Metchnikoff proposed that phagocytic immune cells evolved first as nutritive cells (8). He noted that, across phylogeny, the universal function of digestion was maintained in the process of phagocytosis, irrespective of whether it occurred in the case of food acquisition (intracellular digestion) or in an immune role. Moreover, for single-celled organisms like amoebae, the process of infection and food acquisition are indistinguishable in the initial stages, with the two being separable only by outcome. The evolution of multi-cellularity permitted specialization, including cells devoted to the acquisition of nutrients and defense. In the event of infection, phagocytic cells ingest, destroy, and digest microbes resulting in an outcome that is indistinguishable from single-celled predation. As proposed by Metchnikoff, these cells retain the primordial mechanism of nutrient acquisition, providing continuity between nutritional and defensive roles.

While Metchnikoff saw the connection between digestion and defense, the immune system is composed of many diverse processes beyond the cellular response of phagocytosis and indeed animals most commonly interact with the microbes in their environment through contact with epithelial surfaces. Analysis of such immune and digestive components across animals reveals several remarkable parallels (Table 1), with many enzymes involved in immune responses also having roles in digestion. Given the gut was a major early step in the evolution of metazoa, this tissue is a logical starting point for an analysis of common function.

\section{THE GUT - CONSERVATION AND DIVERGENCE OF DIGESTIVE AND IMMUNE FUNCTIONS}

The gut is ancient in the animal lineage and arose shortly after the emergence of multi-cellularity. The gut is thought to have begun with the formation of a true epithelium, which allowed extracellular digestion, followed by invagination of the epithelium to provide an enclosed space to facilitate the digestive process. The gut later progressed from a one-way digestive tube to the highly organized and specialized organ that is found today in most animals [for more details on the evolution of the gut, see Ref. $(9,10)$ and references therein]. Multiple evolutionary advances of metazoa are attributed to the development and adaptation of the gut (9), as it permitted extracellular digestion and the capacity to digest larger volumes without losing nutrients to diffusion (11). Consequently, the emergence of the gut is thought to have increased energy availability, which in turn may have driven the development of other organ systems.

The gut evolved in a sea of microbes, which posed new challenges and provided new opportunities for nutrition (7). In its most primitive stages, the gut would have provided a new niche that allowed or even invited colonization by microbes. Hosts had to contend with these microbes, either through indifference, forming beneficial associations, eating them, or controlling them to reduce microbial-mediated damage and/or competition for nutrients. While both invertebrates and vertebrates possess innate immune functions, only the latter have adaptive immunity. For this reason, it is thought that the evolution of the immune system paralleled the evolution of the gut, with immunological complexity emerging to protect an increasingly sophisticated digestive tract. In contrast, this essay proposes the alternative view that innate immune defense and digestion were indistinguishable in the primitive gut. 
Table 1 | Examples of dual-use action in digestion and immunity.

\begin{tabular}{|c|c|c|c|}
\hline Component & Type & Digestion/metabolism & Immunity \\
\hline \multirow[t]{7}{*}{ Enzymes } & Proteases & Protein break down & IgA cleavage, toll signal processing \\
\hline & Lysozymes & Cell wall break down & Microbial lysis \\
\hline & Chitinases & Chitin digestion & $\begin{array}{l}\text { Microbial lysis, augment adaptive responses, } \\
\text { wound healing }\end{array}$ \\
\hline & Phenoloxidases & Lignin degradation (fungi, invertebrates) & Melanin synthesis \\
\hline & $\beta 1,3-g l u c a n a s e s$ & Sugar break down & Pattern recognition receptor \\
\hline & Amidases & Cell wall break down & Microbial lysis \\
\hline & Antimicrobial peptides & Cellular break down & Microbial lysis \\
\hline \multirow[t]{3}{*}{ Receptors/signaling } & TIR domain proteins & Foraging & Toxin sequestration \\
\hline & & Response to nutrients & Immune effectors, pathogen avoidance \\
\hline & & Starvation resistance & Pattern recognition receptor \\
\hline \multirow[t]{2}{*}{ Cellular processes } & Phagocytosis autophagy & Food acquisition & Microbial clearance \\
\hline & & Intracellular digestion of food & Microbial clearance \\
\hline
\end{tabular}

This hypothesis has a number of implications for our understanding of the evolution of the immune system. What today are presumed to be disparate primordial functions may not be so. For example, one immediate implication is that intersections between immunity and metabolism may be more intricately linked than previously appreciated $(12,13)$. An immediate parallel is that both pathogen clearance and digestion involve microbial destruction. Hence, enzymes produced for digestion have dual-use function in protection and subsequent evolution of the genes could promote specialization and divergence. For example, $\beta 1,3$-glucanases are digestive enzymes, but one subfamily lost catalytic activity and is a pattern recognition receptor. Similarly, toll-interleukin-1 receptor (TIR) domain proteins in amoebae and an ortholog in C. elegans have dual roles in nutritional foraging and defense $(14,15)$. These dual roles suggest contexts when these functions cannot be distinguished. This may be especially true amongst animals where bacterivory, or the feeding on bacteria as an energy source, provides a major source of nutrition. The role of bacterivory in the origin and evolution of animals is important due to its potential in providing for the acquisition of novel functions through lateral gene transfer $(16,17)$. In this regard, lateral transfer of genes with putative defensive function could have been maintained due to their role as digestive enzymes. For example, two recent reports of genes transferred from bacteria to eukaryotes that were associated with antibacterial activity (one a lysozyme, the other an amidase) could easily function in the digestion of bacteria for nutrient acquisition $(18,19)$. In this regard, lysozymes have historically been categorized into groups as either having defensive or digestive functions, yet they are essentially identical. By and large, the digestive and immune functions of these enzymes has been assigned based on the tissues in which they are expressed, gut or stomach versus immune cells, respectively. However, recent studies have argued that they were preserved through common descent with true homology $(20,21)$.

This hypothesis also suggests alternative views to how the microbiota and the defensive function of the immune system evolved. Considering the emergence of the microbiota, one might envision how microbes that were not digested could be maintained in the gut. In this regard, microbes that contributed to host nutrition by producing a byproduct or transforming compounds could reduce host requirements for microbes as direct food sources, thus permitting their retention. In addition, microbes that are able to resist the digestive processes would have been able to persist in the gut and form potential associations with the host. Alternatively, hosts that evolved gut attributes (physical/physiological) or the ability to selectively digest microbes would be able to maintain a microbiota, which would have been selected for if it provided an advantage. McFall-Ngai (22) has proposed that the evolution of the adaptive immune system may have permitted greater flexibility in the diversity of microbes associated with the gut. Along these lines, the reduced reliance of microbes as direct food sources may have permitted greater diversity of the microbiota and further specialization of epithelial immune responses. In addition, the microbiota is a potential food reserve. Axenic mice are more susceptible to starvation, and starvation of many animals reduces microbiota density, suggesting utilization as food (23-25) Moreover, such phenomenon as termite trophallaxis and digestion of microbiota by nitrogen-deprived herbivores supports the notion that the microbiota can provide a nutritional reserve (26). It is noteworthy that there are $20 \%$ more calories in a gram of microbes than a gram of carbohydrate (27). However, the same microbiota that can serve as food also poses a potential danger to the host as a source of infectious disease. Consequently, these interactions between host and microbiota illustrate the continuity between digestion and immunity.

\section{CONCLUSION}

This hypothesis proposes a common origin for two fundamental physiological systems that are currently viewed as separate and disparate. While the interplay between metabolic and immune pathways, including genes that function in both systems (28) [i.e., foxo (29), MyD88 (30, 31), TGF- $\beta$ (32), mef2 (33), atf3 (34),...] is an area of intense study, these similarities are generally viewed as convergent. In contrast, this hypothesis posits a common origin for these functions, thus providing an explanation for the maintenance of dual functions. I note similar associations in other 
systems, such as Toll having roles in both immunity and development. Underlying these associations is the fact that the ancient function of proteins might be conserved, but can also be co-opted for new roles.

The hypothesis has some practical applications for the interpretation of experiments involving mutants of either metabolic or immune pathways. For example, phenotypes attributed to immune deficiencies, which are often associated with higher microbial burden, could also represent a digestive or metabolic deficiency. An approach to test the hypothesis may be to delete genes that are putatively associated with an immune or digestive function and assess the resulting phenotypes of the other system. By considering a common origin for immunity and digestion, it is possible to integrate metabolic, physiological, and immune information and interpret those data in the context of a unified view.

\section{REFERENCES}

1. Cooper EL. Evolution of immune systems from self/not self to danger to artificial immune systems (AIS). Phys Life Rev (2010) 7:55-78. doi:10.1016/j.plrev. 2009.12.001

2. Muraille E. Redefining the immune system as a social interface for cooperative processes. PLoS Pathog (2013) 9:e1003203. doi:10.1371/journal.ppat.1003203

3. Müller CA, Autenrieth IB, Peschel A. Innate defenses of the intestinal epithelial barrier. Cell Mol Life Sci (2005) 62:1297-307. doi:10.1007/s00018-005-5034-2

4. Lemaitre B, Hoffmann JA. The host defense of Drosophila melanogaster. Annu Rev Immunol (2007) 25:697-743. doi:10.1146/annurev.immunol.25.022106. 141615

5. Harvill ET. Cultivating our "frienemies": viewing immunity as microbiome management. MBio (2013) 4:e27-13. doi:10.1128/mBio.00027-13

6. Bosch TC. Cnidarian-microbe interactions and the origin of innate immunity in metazoans. Annu Rev Microbiol (2013) 67:499-518. doi:10.1146/annurevmicro-092412-155626

7. McFall-Ngai MJ, Hadfield MG, Bosch TCG, Carey HV, Domazet-Loso T, Douglas AE, et al. Animals in a bacterial world, a new imperative for the life sciences. Proc Natl Acad Sci U S A (2013) 110:3229-36. doi:10.1073/pnas.1218525110

8. Tauber AI. Metchnikoff and the phagocytosis theory. Nat Rev Mol Cell Biol (2003) 4:897-901. doi:10.1038/nrm1244

9. Nielsen C. Six major steps in animal evolution: are we derived sponge larvae? Evol Dev (2008) 10:241-57. doi:10.1111/j.1525-142X.2008.00231.x

10. Nyholm SV, McFall-Ngai MJ. Animal development in a microbial world. In: Minelli A, Pradeu T, editors. Towards a Theory of Development. Oxford: Oxford University Press (2014). p. 260-73. doi:10.1093/acprof:oso/9780199671427.003. 0017

11. Raz E. Mucosal immunity: aliment and ailments. Mucosal Immunol (2009) 3:4-7. doi:10.1038/mi.2009.123

12. Ponton F, Wilson K, Holmes AJ, Cotter SC, Raubenheimer D, Simpson SJ. Integrating nutrition and immunology: a new frontier. J Insect Physiol (2013) 59:130-7. doi:10.1016/j.jinsphys.2012.10.011

13. Odegaard JI, Chawla A. The immune system as a sensor of the metabolic state. Immunity (2013) 38:644-54. doi:10.1016/j.immuni.2013.04.001

14. Shivers RP, Kooistra T, Chu SW, Pagano DJ, Kim DH. Tissue-specific activities of an immune signaling module regulate physiological responses to pathogenic and nutritional bacteria in C. elegans. Cell Host Microbe (2009) 6:321-30. doi:10.1016/j.chom.2009.09.001

15. Chen G, Zhuchenko O, Kuspa A. Immune-like phagocyte activity in the social amoeba. Science (2007) 317:678-81. doi:10.1126/science.1143991

16. Alegado RA, King N. Bacterial influences on animal origins. Cold Spring Harb Perspect Biol (2014) 6:a016162-016162. doi:10.1101/cshperspect.a016162

17. Doolittle WF. You are what you eat: a gene transfer ratchet could account for bacterial genes in eukaryotic nuclear genomes. Trends Genet (1998) 14:307-11. doi:10.1016/S0168-9525(98)01494-2

18. Chou S, Daugherty MD, Peterson SB, Biboy J, Yang Y, Jutras BL, et al. Transferred interbacterial antagonism genes augment eukaryotic innate immune function. Nature (2015) 518:98-101. doi:10.1038/nature13965
19. Metcalf JA, Funkhouser-Jones LJ, Brileya K, Reysenbach A-L, Bordenstein SR. Antibacterial gene transfer across the tree of life. Elife (2014) 3:e04266. doi:10.7554/eLife.04266

20. Bachali S, Jager M, Hassanin A, Schoentgen FXO, Jollès P, Fiala-Medioni A. Phylogenetic analysis of invertebrate lysozymes and the evolution of lysozyme function. J Mol Evol (2002) 54:652-64. doi:10.1007/s00239-001-0061-6

21. van Herreweghe JM, Michiels CW. Invertebrate lysozymes: diversity and distribution, molecular mechanism and in vivo function. J Biosci (2012) 37:327-48. doi:10.1007/s12038-012-9201-y

22. McFall-Ngai MJ. Adaptive immunity: care for the community. Nature (2007) 445:153-153. doi:10.1038/445153a

23. Velagapudi VR, Hezaveh R, Reigstad CS, Gopalacharyulu P, Yetukuri L, Islam S, et al. The gut microbiota modulates host energy and lipid metabolism in mice. J Lipid Res (2010) 51:1101-12. doi:10.1194/jlr.M002774

24. Conway PL, Maki J, Mitchell R, Kjelleberg S. Starvation of marine flounder, squid and laboratory mice and its effect on the intestinal microbiota. FEMS Microbiol Lett (1986) 38:187-95. doi:10.1111/j.1574-6968.1986.tb01728.x

25. Taylor EC. Role of aerobic microbial populations in cellulose digestion by desert millipedes. Appl Environ Microbiol (1982) 44:281-91.

26. Fujita AI, Shimizu I, Abe T. Distribution of lysozyme and protease, and amino acid concentration in the guts of a wood-feeding termite, Reticulitermes speratus (Kolbe): possible digestion of symbiont bacteria transferred by trophallaxis. Physiol Entomol (2001) 26:116-23. doi:10.1046/j.1365-3032.2001. 00224.x

27. Prochazka GJ, Payne WJ, Mayberry WR. Calorific content of certain bacteria and fungi. J Bacteriol (1970) 104:646-9.

28. Matarese G, La Cava A. The intricate interface between immune system and metabolism. Trends Immunol (2004) 25:193-200. doi:10.1016/j.it.2004.02.009

29. Becker T, Loch G, Beyer M, Zinke I, Aschenbrenner AC, Carrera P, et al. FOXO-dependent regulation of innate immune homeostasis. Nature (2010) 463:369-73. doi:10.1038/nature08698

30. Everard A, Geurts L, Caesar R, Van Hul M, Matamoros S, Duparc T, et al. Intestinal epithelial MyD88 is a sensor switching host metabolism towards obesity according to nutritional status. Nat Commun (2014) 5:5648. doi:10.1038/ ncomms 6648

31. Ayyaz A, Giammarinaro P, Liégeois S, Lestradet M, Ferrandon D. A negative role for MyD88 in the resistance to starvation as revealed in an intestinal infection of Drosophila melanogaster with the Gram-positive bacterium Staphylococcus xylosus. Immunobiology (2013) 218:635-44. doi:10.1016/j.imbio.2012.07.027

32. Chng W-BA, Bou Sleiman MS, Schüpfer F, Lemaitre B. Transforming growth factor $\beta$ /activin signaling functions as a sugar-sensing feedback loop to regulate digestive enzyme expression. Cell Rep (2014) 9:336-48. doi:10.1016/j.celrep. 2014.08.064

33. Clark RI, Tan SWS, Péan CB, Roostalu U, Vivancos V, Bronda K, et al. MEF2 is an in vivo immune-metabolic switch. Cell (2013) 155:435-47. doi:10.1016/j. cell.2013.09.007

34. Rynes J, Donohoe CD, Frommolt P, Brodesser S, Jindra M, Uhlirova M. Activating transcription factor 3 regulates immune and metabolic homeostasis. Mol Cell Biol (2012) 32:3949-62. doi:10.1128/MCB.00429-12

Conflict of Interest Statement: The author declares that the research was conducted in the absence of any commercial or financial relationships that could be construed as a potential conflict of interest.

Received: 04 November 2014; accepted: 04 February 2015; published online: 19 February 2015

Citation: Broderick NA (2015) A common origin for immunity and digestion. Front. Immunol. 6:72. doi: 10.3389/fimmu.2015.00072

This article was submitted to Microbial Immunology, a section of the journal Frontiers in Immunology.

Copyright (c) 2015 Broderick. This is an open-access article distributed under the terms of the Creative Commons Attribution License (CC BY). The use, distribution or reproduction in other forums is permitted, provided the original author(s) or licensor are credited and that the original publication in this journal is cited, in accordance with accepted academic practice. No use, distribution or reproduction is permitted which does not comply with these terms. 